\title{
Conceptual metaphors in South African political speeches $(1994-2001)$
}

\author{
Saskia Malan \\ Technische Universität Dortmund, Kohlenstr. 48, 45289 Essen, Germany \\ saskia.malan@tu-dortmund.de
}

\section{Introduction}

Metaphor in conceptual metaphor theory as developed by George Lakoff and Mark Johnson (1980) is not merely a rhetorical device but is seen as a structuring device of human thought. This study considers conceptual metaphors within the wider framework of conceptual blending theory (cf., e.g., Fauconnier 1997; Fauconnier and Turner 2002) in which they find themselves as one possible type of blend. The study is based on the assumption that one can deduce basic ways of thinking about and dealing with certain issues from how these issues are talked about, that is, one can get at the roots of how certain concepts are understood, even "thought", by looking at metaphorical expressions used in connection with them. This theory is applied here to political speeches given between 1994 and 2001 by five prominent South African politicians of three major parties, namely the African National Congress (ANC), the New National Party (NNP), and the Democratic Alliance (DA): Nelson Mandela, Thabo Mbeki, Frederick de Klerk, Tony Leon and Marthinus van Schalkwyk. The aim of this study is to detect underlying conceptualisations of key issues and concepts of the early years of the democratic South Africa with special focus on the topics of racism, reconciliation, democracy, nation and the ANC. The paper also considers differences and similarities between conceptualisations, and possible clashes across parties and individual politicians. 


\section{Conceptual metaphor theory}

And it must be remembered that at birth the chameleon is transparent. (Ka' afir) ${ }^{1}$

Conceptual metaphor theory (cf., e.g., Lakoff and Johnson 1980; Lakoff 1982, 1989, 1993, 1996; Gibbs 1994) and blending theory (cf. Fauconnier 1994, 1997; Grady 1999; Fauconnier and Turner 2002) are approaches in the constructivist line of thinking, claiming that reality is not something which exists independently of human knowledge and experience, but that in fact a subjective reality is created by human perception of the world and the processing of this perception. Metaphorical expressions in everyday speech hint at these perceptions and underlying conceptualisations which in turn guide our thinking and acting on the issues concerned. The widely discussed conceptual metaphor POLITICS IS WAR, for example, surfaces in metaphorical expressions such as attacks against the opposition, the cut and thrust of debates - pitting policy against policy and defending the party's right to criticise, providing evidence for POLITICS being understood as WAR. Conceptual blending theory - a theory of the mental operations necessary for the construction of meaning - integrates conceptual metaphors as structuring devices of human thought into its larger framework as single-scope networks, the input whose frame is projected to the blend equalling what is called "source domain" in conceptual metaphor theory (cf. Fauconnier and Turner 2002: 127).

\subsection{POLITICS IS WAR - A basic mapping/blend}

A conceptual metaphor has two input spaces - a source and a target domain. For input spaces to be selected into a mapping or to be fused into a blend they have to exhibit a certain structural similarity. A very schematic illustration of the domains or spaces of POLITICS and WAR could look like that in figure 1. 


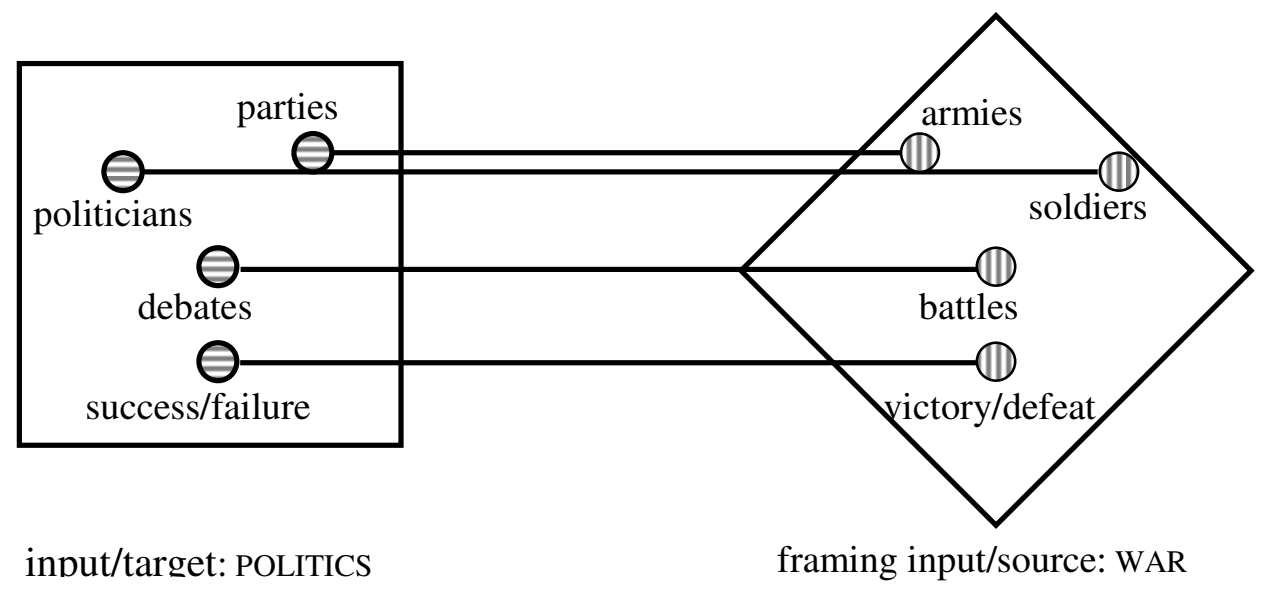

Figure 1. Structural similarities between the domains of POLITICS and WAR

Both input spaces have a certain structure in common - groups of active individuals are interacting, their interaction yielding certain results. This common structure is projected to a neutral generic space, the space which highlights the commonalities and in which the possibility for a mapping becomes obvious. In the blended space the two domains are fused into a new conceptualisation of POLITICS in the frame of WAR, with a new conceptualisation or understanding of POLITICS AS WAR emerging (cf. figure 2). The relationship between the blend and the input spaces is complex: on the one hand the structural similarities give rise to the blend, on the other hand it is only by fusion of these related elements of the two input spaces in the blend that a new conceptualisation is achieved. Some of these new fused elements are, for example, politicians understood to be enemies attacking each other, verbal arguments being physical, armed battles and political positions becoming strongholds which have to be defended. 


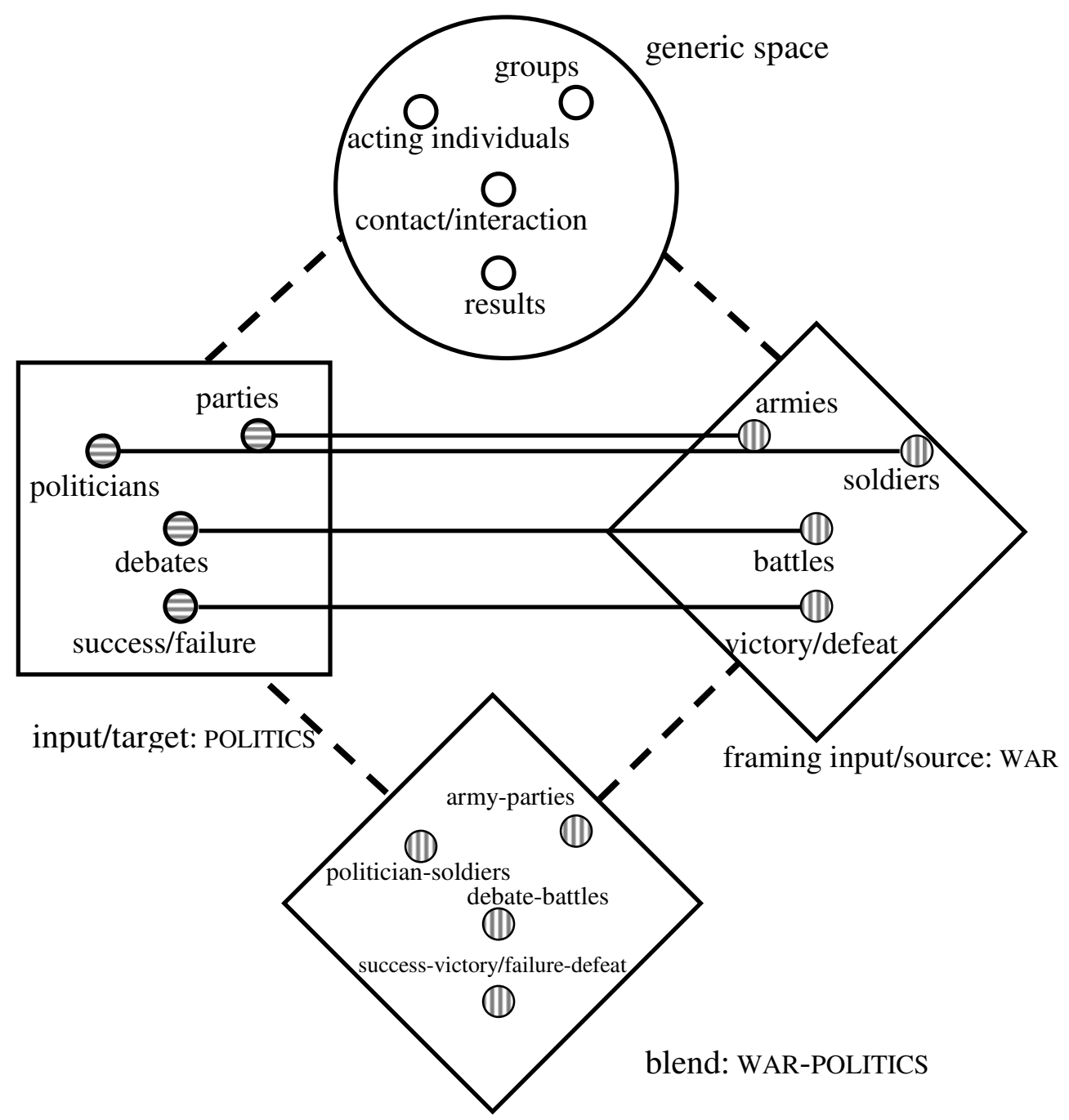

Figure 2. POLITICS-WAR blend

The illustration above is very schematic in nature, not only omitting numerous details of both domains involved, but also neglecting neighbouring and more basic metaphors and blends which support this conceptualisation.

\subsection{A note on the grounding of conceptual metaphors}

The majority of conceptual metaphors are the structural metaphors which make use of more basic-level metaphors - orientational and/or ontological metaphors - at a very early stage. Orientational metaphors depend for one input space on the experience of orientation in threedimensional space (e.g. up-down, in-out, front-back, on-off, deep-shallow and centralperipheral) (cf. Lakoff and Johnson 1980: 14). Ontological metaphors are grounded in the perception of the human body, for example as a bounded entity. 
The grounding of more complex structural metaphors is therefore always at least partly bodily/physical experience, but also cultural experience, as for example in HAPPY IS UP and RATIONAL IS UP. The conceptual metaphor HAPPY IS UP evident in expressions such as I'm feeling up, My spirits rose (Lakoff and Johnson 1980: 15) is rooted in our experience as physical (human) entities moving and living in a three-dimensional space, entities which themselves have a front-back, up-down orientation. Lakoff and Johnson (1980: 15) state that "drooping posture typically goes along with sadness and depression, erect posture with a positive emotional state". However, the basis is less clearly only physical than in, for example, LIFE IS UP, DEATH IS DOWN, as physically displayed features of happiness and sadness are also partly culturally conditioned. Lakoff and Johnson (1980) here refer to physical features of a person's happiness or sadness that are typical of Western cultures but are not necessarily universal.

Clearly mainly culturally based is the conceptual metaphor RATIONAL IS UP; EMOTIONAL IS DOWN (The discussion fell to the emotional level, but I raised it back up to the rational plane, He couldn't rise above his emotions (Lakoff and Johnson 1980: 17)). The explanation Lakoff and Johnson (1980) give is that people in Western culture see themselves as in control over animals and plants. The difference they perceive between themselves and animals or plants is the ability to reason. It is this rationality that gives them control over animals and plants - and since CONTROL IS UP, RATIONAL IS also UP. RATIONAL IS UP has its experiential bases in relatively recent Western history - technological progress has been made by applying rational, logical methods. Rational, scientific thinking is what is required at universities and most people who have a high social status have a university education. HIGH SOCIAL STATUS IS UP (She'll rise to the top, He's at the peak of his career, He's climbing the [social] ladder (Lakoff and Johnson 1980: 16)), because "status is correlated with [social] power" and social power is correlated with physical power and PHYSICAL POWER IS UP. This leads to RATIONAL IS UP from a cultural experiential basis and might be entirely different in a culture where progress is not perceived to be primarily achieved by technological advancement, but where the community relies more on emotional intuitions and beliefs rather than so-called scientific facts.

While conceptualisations acquired through physical or cultural experience shape language, there is evidence form neuroscience that the opposite may also be possible (cf. Elman, Bades, 
Johnson, Karmiloff-Smith, Parisi and Plunkett 2001: 4-6). This means that, through the use of metaphorical expressions referring to different underlying concepts from the ones dominant in a certain socio-cultural group, one might be able to challenge and change these existing conceptualisations.

\subsection{Ritual, culture, convention and metaphor}

Since conceptual metaphor arises from experience, the conceptual metaphors available may differ from individual to individual as much as each individual's experiences differ from those of his or her fellow human beings. People living together in a (socio-cultural) community will have a certain number of common experiences and will therefore share a basic stock of conceptual metaphors. These experiences are conditioned partially by their environment - by the geographical structure of the area they inhabit, the degree of industrialisation, the climate, etc., and partially by traditions and rituals of the community in which they grow up. Ritual here includes a wide spectrum of rituals - religious rituals, rituals developed to deal with momentous and potentially traumatic experiences such as death, but also casual and personal rituals such as the way of remembering the date of birth and the age of a person or the way in which breakfast is prepared. Each ritual, whether on a personal or communal level, is a structured sequence of actions providing guidelines along which everyday chaos is disentangled. They are "experiential gestalts" - multidimensional structured wholes which are more than the sum of their parts - and thereby provide sources for conceptual metaphors. For example, the conceptual metaphor underlying the expression to bury racism arises from an aspect of the ritual of dealing with death and the dead in Western culture. In a culture where the dead are not buried in the ground, but their bodies laid among the branches of old trees, this metaphor would lose its experiential basis and cease to exist. A different conceptual metaphor would be taken to underlie an expression like to bury racism if the only things ritually buried in the ground were seeds. To bury racism would then be taken to stem from a conceptual metaphor like RACISM IS A PLANT and the expression would acquire quite the opposite meaning to that which it has come to carry in Western cultures.

Ritual and traditions are therefore needed to preserve the conceptual metaphors of a cultural community - if the experiential basis is taken away, the metaphor ceases to exist or is transformed. Metaphor can never be entirely understood "independently of its experiential basis" (Lakoff and Johnson 1980: 19, 233ff.). However, each individual's experiences with 
the world do not only condition his/her conceptual metaphors. As much as ritual influences the experience of the world, the metaphorical and linguistic conventions in a community influence the acquisition of metaphorical concepts in the individual. If a child uses the expression to open a light switch s/he has applied the conceptual metaphor formed in connection with opening a door, a window or one's mouth to the events that happen when the light is switched on. This is, however, not a conventional conceptual metaphor in English (though it is in French), therefore the adult members of the community will correct the child and deprive him/her of this extension of the conceptual metaphor concerning opening something (cf. Rumelhart 1993: 73). A linguistic community preserves its way of thinking by preserving its language.

If cultural and linguistic communities are deprived of their rituals and language - as has happened during colonialism - they may lose their structure of thought and their way of looking at the world. Thereby the whole of humanity may be deprived of a part of its knowledge of the world, as a few of the lights illuminating different aspects of one concept are extinguished.

\section{Metaphor in South African political speeches}

The first democratic elections in South Africa in 1994 marked the beginning of a new phase of transformation, and started a difficult phase of South Africa's history - old norms had been overturned and new ones were and still are in the process of being established. Radical rethinking was and is taking place on an individual but also on a national level. This study takes a look at how some of the main issues and problems of the "New South Africa" are conceptualised by South African politicians.

\subsection{Structure of the study}

For the analysis of conceptual metaphors a selection of speeches by five South African politicians from three major South African political parties was made. Speeches of the following politicians are included:

1. Nelson Rolihlahla Mandela (leader of the ANC until 1997, and president of the Republic of South Africa from 1994 to 1999) 
2. Frederick Willem de Klerk (leader of the National Party (NP) from 1990 to 1997, second deputy president under Nelson Mandela and former president of the Republic of South Africa)

3. Thabo Mvuyelwa Mbeki (leader of the ANC since 1997, first deputy president under Nelson Mandela and president of the Republic of South Africa since 1999)

4. Tony Leon (leader of the DA since its formation in 2000 until May 2007, former leader of the Democratic Party (DP))

5. Marthinus van Schalkwyk (leader of the NNP since 1997, deputy leader of the DA since 2000, became a member of the ANC in 2004)

The speeches contained in the corpus have been selected from the speeches given by the five politicians between 1994 and September 2001. Besides date and speaker, the topic of the speech was an additional criterion for selection to obtain comparable data. Topics selected were major issues which were addressed on a national rather than provincial level, like the future of South Africa, racism, reconciliation, social equality and equal opportunities.

The final corpus for the present study consists of 30 speeches, between five and eight per speaker, depending on the length of the single speeches. In each speech the metaphorical expressions were marked, indexed and sorted according to source and/or target domains. In this way conceptual metaphors were discernable from the collections of expressions. The index of each metaphorical expression consists of the initial(s) of the speaker $(\mathrm{nm}=$ Nelson Mandela, $\mathrm{tm}=$ Thabo Mbeki, $\mathrm{K}=\mathrm{FW}$ de Klerk, $\mathrm{L}=$ Tony Leon, $\mathrm{S}=$ Marthinus van Schalkwyk), the last two digits of the year in which the speech was held and a small letter, if there are several speeches from the same year in the corpus. For example, the index S01g indicates that this metaphorical expression was used by DA Deputy Leader Marthinus van Schalkwyk in speech $\mathrm{g}$ of the year 2001. The complete list of speeches contained in the corpus, giving the titles, sources and indexes appears in the reference list.

\subsection{Aim and outline of the study}

The aim of the study is to point out conceptual metaphors of major issues in contemporary South African politics, such as reconciliation, racism, nation and democracy. As conceptual metaphors arise from experiences, an attempt is made to identify their bases in order to explain the origin of conceptualisations. The study investigates whether the concepts South 
African politicians "live by" differ between ANC and DA/NNP politicians. Since the ANC and DA/NNP politicians whose speeches have been analysed come from different ethnic backgrounds this could legitimately be expected. On the other hand, they share a certain amount of experience, having lived under the apartheid system, and witnessed and engaged in its demise and the following radical changes in South African political and social structure. Therefore the analysis could arrive at a contrary result and find little difference between the concepts underlying ANC and DA/NNP politics. Even if this is the case, the results provide an impression of the conceptual metaphors directing South African political thought.

\subsection{The conceptualisation of nation}

\subsubsection{What is a nation?}

To define a group of people as a nation implies that they have certain commonalities otherwise there would be no basis on which to group them. Commonalities may for example be a common history, common traditions, a common general culture, a common language, maybe even certain common physical features, common structures of thought - but probably most people have to feel that they somehow belong together. At least some of these criteria have to be met to start thinking about calling a group of people a "nation".

If this rough description of a nation is applied to the situation in South Africa, the Republic of South Africa is a state with many nations. The different communities have neither a common history - even the relatively recent period of apartheid held entirely different experiences for them - nor common traditions, a common culture or a common native language. There is little ground on which the feeling of being one nation could be based. Halisi (1999: 2ff.) mentions the concept of 'dual citizenship' which in this context refers to the potential identification of the individual South African with his ethnic groups and with a larger South African nation. This, however, could at most be said for a small part of the South African population, since many people will not have been able to identify with the oppressive system of apartheid (cf. Halisi 1999: 2-7).

Nonetheless, the desire to build one nation appears to be strong among South African politicians. This however, proves a very difficult project. The estrangement of different ethnic groups within South Africa through apartheid, mostly along "colour-lines", appears to have worked very effectively, leaving people with little common ground for a common nation to 
gain a foothold. Nonetheless, it is seemingly the only way politicians see for a South African state to survive.

\subsubsection{The conceptual metaphor A NATION IS A BUILDING}

The majority of metaphorical expressions used with reference to 'nation' stem from the underlying metaphor A NATION IS A BUILDING, as evident in the following examples:

(1) building the nation ${ }_{n m 95 c}$

(2) We must therefore act together as a united people [...] for nation building $\mathrm{nm} 94$

(3) we will continue to give our whole-hearted support to the Government's efforts to [...] build a strong and united nation $\mathrm{K} 96 \mathrm{e}$

(4) to build a nation from a country kept apart L01b $_{\text {b }}$

(5) able to really build a rainbow nation SO0b $_{\text {ba }}$

(6) But the public of South Africa look to the President to advance the stalled process of reconciliation and nation building in our country s01g

The South African 'nation' is conceptualised by South African politicians as something which has to be constructed. It is not conceptualised as a natural occurrence or a living being that has the potential to grow (by itself), but an artificial, man-made construct. This stands in contrast to the common metaphor which envisages South Africa as the rainbow nation - the rainbow being an amazing natural phenomenon which is entirely out of the control of humankind.

While the construction of a nation is sometimes seen as a process which is advanced by machines which do not always work smoothly (cf. (6)), other expressions still allow for the human factor (cf. (2) and (3)) by mentioning the builders (a united people) and referring to the specifically human characteristic of emotion - whole-hearted support.

The metaphor A NATION IS A BUILDING implies that there is a piece of ground suitable for building upon. If - as is the case in South Africa - no such basis exists, the first step must be to create it.

(7) The new nation that we envisaged could not be founded on common culture, language and tradition as are most other nations ${ }_{\mathrm{K} 96 \mathrm{c}}$ 
(8) [the nation] would be built on common values and aspirations contained in a new constitution ${ }_{\mathrm{K} 96 \mathrm{c}}$

(9) the concept of one nation, built on newly discovered commonalities, and on the basis of a shared patriotism $\mathrm{S00b}$

(10) If the motivation is to find solutions to really build a new nation based on new common experiences, then the present debate is counter-productive ${ }_{\mathrm{S} 00 \mathrm{~b}}$

(11) You cannot one day tell people how bad they are, how guilty they are, that they should be taxed on the basis of their skin colour, and the next day give them a pat on the head and believe that this will provide a basis for [...] building a strong nation on common ideals and experiences so0b

Recognising that a basis for a common culture, language and tradition (cf. (7)) was not available for the South African nation to be built upon, the speakers provide alternatives. For the two members of the New National Party, the foundation of the future South African nation consisted of common values and aspirations (cf. (8)), common ideals (cf. (11)), shared patriotism (cf. (9)), or even more general new common experiences (cf. (10)) and commonalities (cf. (9)). They stress the importance of common attitudes and common structures of thought for the basis of a nation.

Mandela suggests a similar attitude in (12). The preparation of the ground here is the creation of hope, i.e., of a positive attitude toward the project. This contrasts starkly with a metaphorical expression used by Mandela to describe the pre-1994 situation (cf. (13)).

(12) leaders should emerge from all parties and from all walks of life to build the nation on the basis of hope for a future that we should create together ${ }_{n m 99 a}$

(13) Two terrible defects weakened the foundations of the modern South African state [...] it rested on the treacherous swamps of racism and inequality ${ }_{\mathrm{nm} 95 \mathrm{c}}$

Mbeki adds another aspect of the foundation - the material resources, as in (14), whereas Van Schalkwyk extends the metaphor to the kind of material needed for the construction of a building, like cement or mortar and bricks, as in (15). 
(14) the creation of the material conditions that would both underpin and represent nation building $_{\mathrm{tm} 98 \mathrm{a}}$

(15) Hope for building a new nation, united by a single South African pride and patriotism S01a

(16) Reconciliation is an indispensable ingredient in the process of building one nation s01f

Pride and patriotism are here no longer only part of the foundations, but also the mortar of the NATION-BUILDING. Reconciliation is an essential ingredient in the cement-mixture. This adds a new aspect to the material of the nation-building - the parts are not stacked upon one another, but mixed together. While the speakers emphasise different aspects, all agree on the conceptualisation A NATION IS A BUILDING.

\subsubsection{The conceptual metaphor A NATION IS A FAMILY}

The conceptualisation of A NATION AS A BUILDING contrasts with conceptualisations of NATION AS A PERSON or FAMILY that Lakoff has found in American (i.e. USA) political thought (cf. Lakoff 1992, 1996). There are some instances of metaphorical expressions which hint at a conceptual metaphor of A NATION IS A FAMILY in South African political thought as well.

(17) the success of each nevertheless depends on the effort the other will make to turn into reality the precept that each is his or her brother's or sister's keeper ${ }_{\text {tm98a }}$

(18) I would like to say to my white, coloured, and Indian brothers and sisters s01c

Labelling all South Africans as siblings implies that they have a common origin. Another conceptual metaphor which implies a common origin is the metaphor A HUMAN BEING IS A PLANT (as in, for example, to flourish as a community ${ }_{\mathrm{nm} 98 \mathrm{a}}$ ), evident in the expression by Van Schalkwyk in (19).

(19) I would like to see black, white, coloured and Indian South Africans accept the bona fides of all people who say: come let us acknowledge and respect our common roots, even though we have historically viewed them from different perspectives. s01c

This metaphorical concept is used not nearly as often and as systematically as the one of A NATION IS A BUILDING in the speeches analysed. At first sight this is surprising, as the 
conceptual metaphor A NATION IS A FAMILY may have the power to diminish antipathy among ethnic groups, if it could be established as a structure of thought. An explanation for the few instances of this metaphor, however, might be that the relationships among the different South African ethnic groups are not yet close enough for the source FAMILY to find sufficient correspondences in the target NATION and for the metaphor of A NATION IS A FAMILY to become a structural metaphor for South African thought. Moreover, the concept of family itself - essentially Western in origin - and the socio-cultural attitudes towards it are divergent among the ethnic groups.

The instances of A NATION IS A FAMILY occur only in one of Van Schalkwyk's speeches - in the speech held after visiting the home-town of chief Albert Luthuli, the visit being closely covered by the press. Therefore it seems likely that the terms "brother" and "sister" are consciously used here to create an impression of equality, but are not yet to be seen as evidence for underlying conceptual metaphors.

\subsection{The conceptualisation of democracy}

Democracy as the new form of government after apartheid promised every group and every individual a certain amount of participation in the future of South Africa. It is, however, not enough to merely fix democracy as the form of government in the constitution - people also have to learn to live under the system of democracy as, for example, the history of the German Republic of Weimar shows. This attitude is apparent in the utterances of South African politicians.

(20) the gift of hope delivered to the people by the birth of democracy $y_{\mathrm{tm} 98 \mathrm{a}}$

(21) Our decision should be seen as an important step in the growing maturity and normalisation of our young democracy.K96e

(22) our young democracy has come of age ${ }_{n m 96 b}$

(23) Vigorous, healthy debate is the lifeblood of democracy. s01g

Democracy is conceptualised as a child. It was born in 1994 as a new form of government for South Africa, and nobody yet knew how it would develop (cf. (20)). As the system of democracy is applied to the South African state, people get to know it and learn how to cope with it; it is seen as growing up and maturing (cf. (21)) until it is eventually - ideally - a 
responsibly acting adult (cf. (22)). The attention then turns to the maintenance of this democracy-person's abilities and health - vigorous debate is a life-sustaining part of democracy (cf. (23)).

By conceptualising democracy as a child or person people perceive it as something which needs protection and care and to which one is emotionally attached. It places the South African people in the position of parents - they have the responsibility for its development. The democracy-child needs to be looked after; it needs guidance to differentiate right paths from wrong paths and to learn to conform to the norms of the culture until it can eventually look after itself. It is something worth being defended against opponents (possibly even in war) as expressed in (24).

(24) Reconciliation requires that we work together to defend our democracy and the humanity proclaimed by our constitution. nm98a

Parenthood is an essential part of human experience which all humans share independently of their culture. But DEMOCRACY IS A CHILD might entail a number of consequences depending on cultural differences in child-rearing practices. For example, in a culture where beating children is still an acceptable means of "showing children the right path", violent actions to obtain the right form of democracy might not be unimaginable.

Two other metaphorical expressions appeared in the corpus which are linked to DEMOCRACY IS A CHILD, as in (25) and (26). A common and inclusive agenda and multi-culturalism, tolerance and respect for diversity are all aspects of the Western understanding of democracy. They are viewed as young beings (children or plants) which have to be cared for. This conceptualisation of tolerance etc. contrasts sharply with the conceptualisation of racism. While racism is something to be fought and destroyed, tolerance needs to be protected and cared for.

(25) A commitment to a common and inclusive national agenda must be nurtured.s01b

(26) for South Africa to build on its success of the past decade, we need to foster multiculturalism, tolerance and respect for diversity ${ }_{\text {L } 01 \mathrm{~h}}$ 


\subsection{The conceptualisation of racism}

Race is not a sentence, it is just a word. soob

Racism in all its forms is viewed in the analysed speeches as a consequence of colonialism and the apartheid system in which racist thinking was enforced, if only through estrangement of the different ethnic groups. In some of the examples in this section, therefore, the terms "apartheid" or "colonialism" are used synonymously with racism against black people.

\subsubsection{The conceptual metaphor RACISM IS AN OBSTACLE}

Racism is conceptualised as an obstacle which is only overcome with difficulty (cf. (27) to (29)).

(27) It is not possible to over-emphasise this particular imperative [for the white section of the population to recognise the reality of racism], so central is its place among the panoply of initiatives we must take in the common struggle to end racism $\mathrm{tm00b}_{\mathrm{b}}$

(28) throughout a very long period of struggle against racism tmoob $_{\text {b }}$

(29) the Apartheid system and the struggle against it L00

The concept of RACISM AS AN OBSTACLE is related to and supported by the widespread metaphor LIFE IS A JOURNEY. The path on which the South African people travel is made more difficult or is even blocked by the obstacle of racism. The destination that they want to reach is a reconciled nation, as in (30).

(30) therefore take us forward towards the realisation of the objective of reconciliation and nation building tm98a

The expressions in the examples in (31) to (36) are situated in a continuum between struggle (against possibly (only) an object blocking the way) and war (against a (human) enemy).

(31) [we] will make an important contribution to the universal struggle to defeat the scourge of racism ${ }_{\mathrm{tm} 00 \mathrm{~b}}$

(32) unite in struggle against racism until victory is achieved $\mathrm{tm}_{\mathrm{tm} 1 \mathrm{~b}}$

(33) combatants in the global struggle for the defeat of the apartheid system $\mathrm{tm} 01 \mathrm{~b}$ 
(34) victorious fellow combatants in the struggle that finally liquidated the system of colonialism tm01b

(35) In welcoming you to South Africa, we welcome you as fellow combatants who joined us in struggle to defeat and suppress the apartheid crime against humanity tm01c

(36) These masses are convinced that when you waged that protracted struggle, you did so because you were opposed to racism ${ }_{\mathrm{tm} 01 \mathrm{c}}$

Both struggle and war imply "forceful or violent" action, but war is associated with "armed hostility" between two active opponents (The New Oxford Dictionary of English 2000). ${ }^{2}$ The picture arising from the mix of the two concepts, combining struggle with verbs (defeat, wage a war), nouns (combatants) and adjectives (victorious) that collocate with war, is a picture of racism, apartheid and colonialism as an entity so strong and settled that although it does not actively fight back, all resources of war are needed to overcome it.

\subsubsection{The conceptual metaphor RACISM IS AN OPPONENT}

The dominating conceptual metaphor of racism apparent in the speeches analysed is RACISM IS AN OPPONENT (IN WAR), as reflected by the examples in (37) to (44).

(37) a constitutional and legally guaranteed right to equality and non-discrimination is very important in the fight against racism tm00b $_{\text {b }}$

(38) how to combat racism ${ }_{\mathrm{L} 00}$

(39) [other countries] with whom we have combined, to form a world army of peoples united against racism $_{\mathrm{tm} 01 \mathrm{~b}}$

(40) we combine to defeat the consequences of slavery, colonialism and racism $\mathrm{tm}_{\mathrm{tm}} \mathrm{c}$

(41) a democratic South Africa gave us an additional combat base from which we would sustain our offensive to eradicate all expressions of apartheid injustice everywhere else in the world ${ }_{\text {tm01b }}$

(42) Our constitutional and legal framework and regime provide us with a strong legal base to confront the scourge of racism. tm00b

(43) it will take time for us to wipe out this legacy [of apartheid and colonialism] tm00b $_{\mathrm{b}}$

(44) none but the dim-witted and those deranged by fanaticism dare stand up and openly hoist the racist and sexist standards of the past $t_{\mathrm{tm} 01 \mathrm{~b}}$ 
RACISM IS AN ENEMY IN WAR - an enemy who needs to be defeated and over whom total victory can only be gained by its destruction. Racism seems to be a particularly strong enemy, since only united action of all people(s) will possibly be able to cope with it. Racism is conceptualised as an object, possibly even an intelligent being which is capable of conducting a war. It is conceptualised as being unconnected to human beings - ignoring the fact that racism is man-made and does not exist independently of human beings. It is striking that the examples above - RACISM AS AN OBSTACLE as well as RACISM AS AN OPPONENT - stem mostly from speeches by Thabo Mbeki, only two instances of this metaphor were found in speeches by Tony Leon. Mbeki uses this conceptual metaphor systematically, as the examples in (45) to (47) show.

(45) such a discussion, about racism, can only lead to the division of our country into mutually antagonistic racial camps $s_{\mathrm{tm} 00 \mathrm{~b}}$

(46) the perpetrators and beneficiaries of racial oppression and exploitation have acted merely to defend their interests, refusing to extend their own hand towards the victim, in a true spirit of reconciliation ${ }_{\text {tm00b }}$

(47) very few of our white compatriots broke ranks with the system of white minority rule to join the black millions who were in rebellion against racist rule tm00b $_{\text {b }}$

Mbeki also provides an interesting variation on the RACISM IS AN ENEMY metaphor, as reflected in (48) to (50).

(48) as a people, both black and white, we have the wisdom, ingenuity and sensitivity to the human condition that will drive and enable us to overcome the demon of racism ${ }_{\mathrm{tm} 00 \mathrm{~b}}$

(49) defeat the demon of racism tm00b

(50) [to] bury the demon of racism $\mathrm{tm} 01 \mathrm{~b}$

Here the shape of the enemy is more closely defined - it is a demon, an evil spirit. This attributes supernatural abilities to the phenomenon of racism and consequently entails that racism is not only difficult to fight, but requires unusual weapons. It possibly even has the ability to escape our perception because it is a spirit. The concept of demon or evil spirit is present in most, if not all religions although it is of differing importance. Depending on how 
present the belief in demons is in a certain culture the metaphor might gain varied associations.

Leon offers one instance of a metaphorical expression in one of his speeches which hints at a similar concept of the supernaturalness of racism and of the difficulty in dealing with it (cf. (51)). This is the only instance of such an expression in Leon's analysed speeches. The only instance in which Van Schalkwyk was found to elaborate on the metaphor RACISM IS AN OPPONENT IN WAR is given in (52), where certain tactics are suggested by which to conduct the war.

(51) Racism is South Africa's curse L00

(52) What is needed in South Africa to address issues of racism is a two-pronged approach: The first prong is a normative legislative one. [...] By far the more important prong is the necessity for positive action and constructive nation-building soob

However, Van Schalkwyk uses expressions of the metaphor RACISM IS AN OPPONENT IN WAR far less systematically than Mbeki. The origin of Mbeki's systematic use could lie in his own experience of the apartheid system and the activities of the ANC in overthrowing it. Although he did not himself fight in the armed struggle, he grew up in an environment where the violent physical fight against the apartheid system was the dominant form of resistance. This could explain the mapping RACISM IS AN OPPONENT IN WAR which is so obvious in his speeches.

Mbeki's language might appeal especially to people who have experienced the armed resistance as a carrier of hope for a future without apartheid and thereby earn him their votes. But establishing this metaphor further through constant use could also endanger the peaceful process of reconciliation. It seems unlikely that it is possible to talk about a topic in a language of war and still deal peacefully with it. On the other hand, a common enemy can unite those who were bitterly opposed before. From the speeches of Thabo Mbeki it would appear that racism fulfils this role of a common enemy for South Africans. 


\subsubsection{The conceptual metaphor RACISM IS AN OPPRESSOR}

The metaphor RACISM IS AN OPPRESSOR is also discernable in Mbeki's speeches. It is certainly linked to the metaphor RACISM IS AN OPPONENT, but has a slightly different perspective.

(53) we rose against apartheid racism tm01c $_{\mathrm{c}}$

(54) this country which you helped to liberate from apartheid racism tmolc $_{1}$

(55) this liberated area [post-apartheid South Africa] tm01b

(56) very few of our white compatriots broke ranks with the system of white minority rule to join the black millions who were in rebellion against racist rule tmo0b $_{\mathrm{b}}$

Racism here is, for example, a dictator in an oppressive system against whom the oppressed united. This image is evoked with special reference to the demise of the apartheid system which associates the change closely with a military putsch, although the final transition was in fact a relatively peaceful process. It falsifies the perception of the past and accentuates similarities to changes of regime in other African states such as The Congo and Rwanda. It misses the chance to differentiate South Africa from other African states in this respect and thereby unnecessarily gives away a major advantage over developments in other African states.

\subsubsection{The conceptual metaphor RACISM IS A DISEASE}

A metaphor which highlights the evasiveness and also inevitability of racism in contrast to, for example, the metaphor RACISM IS AN OPPONENT IN WAR, is the metaphor RACISM IS A DISEASE.

(57) we have lost sight of the only real antidote to racism $\mathrm{L00}$

(58) [we are searching] for an antidote to this poison of our nations soul [i.e. racism] L00

(59) a country that, in many respects, represented the most malignant expression of a cancer, racism tm01b

(60) The old South Africa was like a cancer patient with a deadly tumor - the tumor of racism $_{\text {soob }}$

(61) Visionaries in the form of Mandela and De Klerk stepped in and applied radical treatment soob 
(62) We all believed the cancer of racism was in remission and the patient well on the way to recovery. Over the last year, however, we have suddenly discovered that the tumor is back $\mathrm{s} 00 \mathrm{~b}$

Metaphorical expressions leading to the assumption of an underlying metaphorical concept of RACISM IS A DISEASE are mainly found in speeches by Leon and Van Schalkwyk. Leon stresses the search for an antidote, which implies that there is one specific solution to the problem of racism, and that, once this is found, racism will quickly cease to exist and cease to pose a threat to anyone. It hides the aspect that racism is not inflicted on someone by something nonhuman, but is essentially man-made. Conceptualising work to be done to overcome racism as an "antidote" hides the essential aspect that the solution cannot be found outside of human beings and cannot simply be swallowed or injected to make racism disappear.

Van Schalkwyk - and in one expression also Mbeki - talk of racism as cancer, a deadly disease for the persons suffering from it. This links up with A NATION IS A BUILDING and RACISM AS A DIVIDING FORCE. If racism is not "cured", the united South African nation will not survive, or rather not even come into being.

In general RACISM IS A DISEASE is preferred by DA politicians to RACISM IS AN OPPONENT IN WAR. It accentuates that measures other than violent action have to be taken to deal with racism. Still it evokes the image that only especially trained people can find and apply these measures - it does not draw attention to the fact that non-racism and tolerance can and has to be practised by everybody to overcome prejudices.

\subsubsection{Other conceptualisations of racism}

Racism is a very complex concept - it is an abstract concept, a phenomenon that becomes obvious only in the interaction of human beings. In order to deal with it, even to address it, it needs to be conceptualised as an object of some kind before specific properties can be assigned to it. Because it is so complex, various conceptualisations are possible, highlighting different aspects. In addition to the most widely used conceptualisations mentioned above, several expressions were found in the limited corpus of this study which hint at other underlying metaphors, such as that in (63). 
This metaphor highlights the familiarity with racism that South African society has acquired and the responsibility that every South African has in acting against racism. This aspect is not at all present in the example in (64), which rather highlights the pervasiveness of RACISM and its superhuman power, i.e. AS A FORCE IN WATER, a current. This metaphorical expression is linked to LANGUAGE IS WATER (e.g. to speak a language fluently). It "flows" from one person to another, carrying information of some kind. But it can have hidden meaning or convey attitudes which the speaker does not state openly - the undercurrents. But also RACISM itself is conceptualised AS WATER, as in (65).

(64) But the debate in this Chamber has started to degenerate into the pre-1994 style of debate where undercurrents of racism and racial slurs are often seen as the way of attempting to win $\mathrm{S} 01 \mathrm{~g}$

(65) this country, which not so long ago was the fountainhead of racism $\mathrm{tm}_{\mathrm{tm}}$

The aspect highlighted by this metaphor in (65) is that racism can spread from one person to the next, from one community to the next, from one generation to the next, etc., which links it to RACISM IS DISEASE and RACISM IS AN EARTHQUAKE, as is apparent in (66).

(66) [South Africa became] the epicentre of the state-approved ideas of racism, to which all humanity could legitimately attribute such anti-human phenomena as racism and anti-semitism, slavery and colonialism ${ }_{\mathrm{tm} 00 \mathrm{~b}}$

The conceptualisations of racism discussed above form a complex network, but two main strands can be made out along which metaphors are spaced. One strand leads to a conceptualisation of racism as an entity with clearly defined borders which exists outside and independently of human beings (e.g., obstacle, opponent, force). The other strand leads to a conceptualisation of racism as a very diffuse entity, difficult to get a hold on and not entirely independent of human beings (e.g., disease, person). 


\subsection{The conceptualisation of reconciliation}

"Reconciliation" has been a key word in South African history since 1994. To enable reconciliation to take place and to accelerate it on a nation level the Truth and Reconciliation Commission (TRC) was founded. Reconciliation is a topic which touches people deeply as so many have been involved in some kind of politically or racially motivated violence.

\subsubsection{The conceptual metaphor RECONCILIATION IS THE DESTINATION OF A JOURNEY}

The metaphor RECONCILIATION IS THE DESTINATION OF A JOURNEY is part of a complex network of metaphors around the metaphor LIFE IS A JOURNEY.

(67) racial conflict, destroying the progress we have achieved towards national reconciliation $_{\mathrm{tm} 00 \mathrm{~b}}$

(68) to take to the long road towards the eradication of the legacy, which is our daily companion, of slavery, colonialism and racism ${ }_{\mathrm{tm} 01 \mathrm{c}}$

(69) The challenge that we face in taking the TRC process forward is to focus in particular on the special additional measures that we need to undertake to reach the ideal of reconciliation $_{\mathrm{nm} 99 \mathrm{a}}$

(70) [racism is $]$ a dead end street which could only end in crisis and misery $\mathrm{k} 97 \mathrm{a}$

(71) the quest for reconciliation was the fundamental objective of the people's struggle ${ }_{n m 99 a}$

(72) The quest for reconciliation was the spur that gave life to our difficult negotiations process and the agreements that emerged from it ${ }_{\mathrm{nm} 99 \mathrm{a}}$

(73) to break down these human-made barriers [i.e. racism] that block what should be an open road to a new world of justice, equality and dignity for all human beings tm01b

(74) we must break out of this tortuous racial mindset if South Africa is ever to achieve reconciliation $_{\mathrm{L} 00}$

(75) People like myself believe that reconciliation cannot wait indefinitely s01f

(76) there are growing signs of a back-slide towards the politics of division and the deterioration of race relations. solh

The life of a nation, its history and development, is conceptualised as a journey. This builds on the metaphor A NATION IS A PERSON (cf. Rohrer 1995). On this journey, the destination of which is reconciliation, the nation as traveller encounters obstacles, but also things which lead it astray. One obstacle is racism (cf. (73)). The nation has to stay on the right track; if it takes 
a wrong turn it might end up in a dead-end street (cf. ((70)) or go in circles (cf. (74)) and never reach the reconciliation-object or reconciliation-person. Travelling along the right path is not easy; it is an up-hill journey (cf. (76)), linking it to the basic level metaphor GOOD IS UP. The adventurous and unpredictable aspect of this journey is highlighted in example (71) when the journey is called a "quest". The quest for reconciliation is also referred to in example (72), however, the network of metaphors underlying the metaphorical expressions in this example is more complex. Seeing RECONCILIATION AS THE DESTINATION OF A JOURNEY and wanting to reach this destination provided the motivation to negotiate - even more than that, it ensured the existence of negotiations, it gave life to negotiation. RECONCILIATION AS THE DESTINATION OF A JOURNEY is conceptualised as a PRODUCTIVE FORCE. It might even be possible that the relation of the desire for reconciliation, negotiations and agreements is conceptualised in terms of parents and offspring, whereby each "gives birth" to the next "generation". This highlights the causal relationship between the quest for reconciliation, negotiation and agreement and their mutual dependency. Without the desire for reconciliation, without a common objective, there would be no basis for negotiations, and without negotiations there would be no agreement. This analysis presupposes that one conceptualisation of logical dependency takes place in terms of parent and offspring. There is, however, no further evidence to support this hypothesis in the present study.

The conceptualisation of RECONCILIATION AS THE DESTINATION OF A JOURNEY potentially has a uniting effect on South Africans - they are all travellers on the same road, therefore they form a community, a nation. A conceptualisation of reconciliation which is related to RECONCILIATION IS THE DESTINATION OF A JOURNEY because it builds on the same metaphors, but still offers an opposing perspective on reconciliation, is expressed in the examples by Van Schalkwyk in (77) and (78).

(77) Without the necessary support structures to take reconciliation forward, the process remained incomplete s01a

(78) Reconciliation and nation-building must be carried forward $\mathrm{s} 01 \mathrm{~h}$

Here reconciliation seems to be conceptualised not as the destination of a journey but as an object which is taken along on the journey of the nation-person. Reconciliation becomes an 
integral part of the journey into the future (FUTURE IS AHEAD), opposing the notion that reconciliation stands at the end of a common journey.

\subsubsection{The conceptual metaphor RECONCILIATION IS A CONSTRUCTION}

RECONCILIATION IS A CONSTRUCTION is related to the metaphors A NATION IS A BUILDING and RACISM IS A DIVIDING FORCE. As can be seen (79) to (81), Mandela and Leon refer to RECONCILIATION AS A CONSTRUCTION, although the kind of construction they have in mind differs. Mandela uses the metaphor of RECONCILIATION IS A BUILDING and refers to the foundations as well as to the complete building. Leon, on the other hand, uses the metaphor of RECONCILIATION IS A BRIDGE, which is linked to RACISM IS A DIVIDING FORCE.

(79) it [the TRC] has contributed to the work in progress of laying the foundation of the edifice of reconciliation. The further construction of that house of peace needs my hand. It needs your hand. nm98a

(80) that it is possible to break down racism and build bridges of common understanding L00

(81) We must also break down racist assumptions and build bridges of reconciliation and understanding between communities L00

These two metaphors again provide evidence that conceptual metaphors form a coherent system - and what is more, that this system holds for politicians from all parties. The expressions used by Leon, leading to the assumption of the metaphor RECONCILIATION IS A BRIDGE (cf. figure 3), fit very well with his own expressions of the conceptual metaphor RACISM IS A DIVIDING FORCE, but also with the expressions used by Mandela and Mbeki who talk of walls of racism which Leon wants to "break down". 


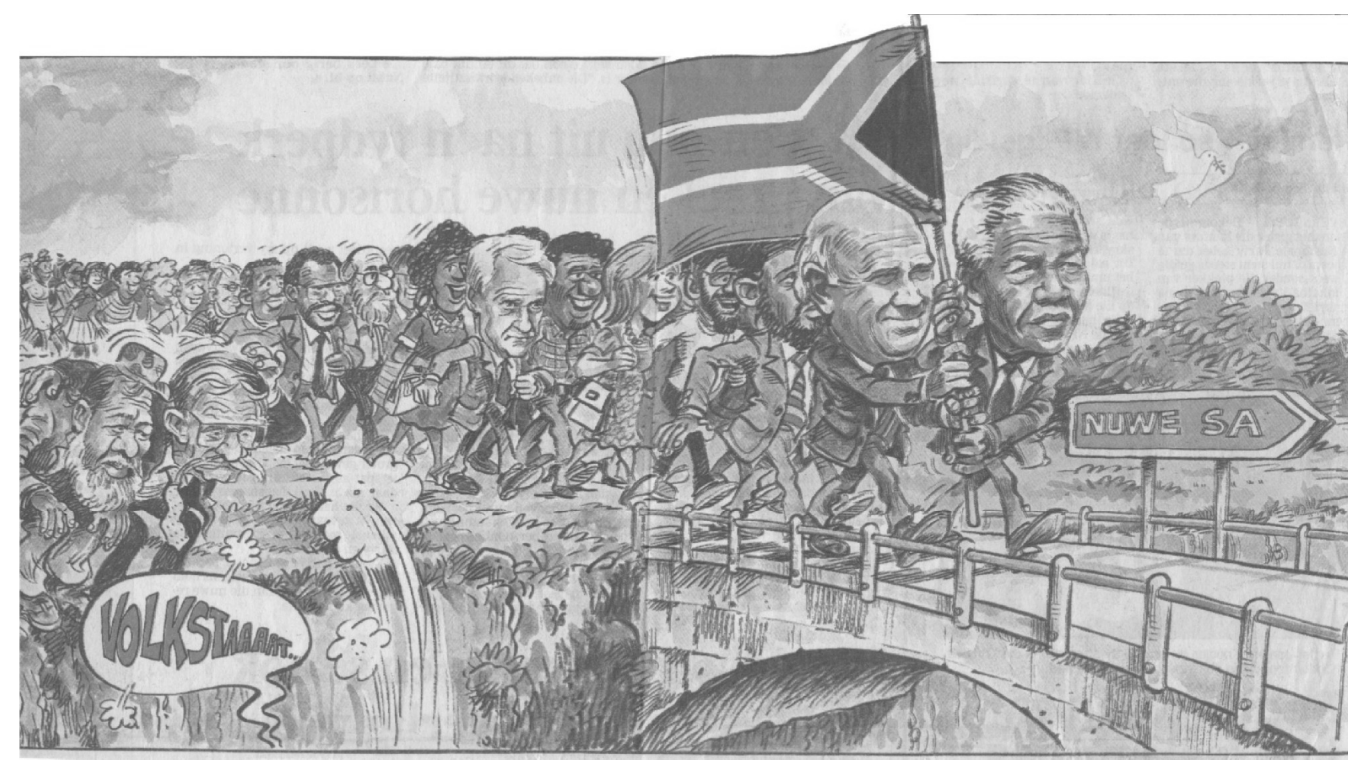

Figure 3. RECONCILIATION IS A BRIDGE INTO THE FUTURE of a New South Africa ("Nuwe SA") (Beeld, 27.4.1994)

\subsubsection{The conceptual metaphor RECONCILIATION IS HEALING}

The metaphor RECONCILIATION IS HEALING is part of the network of conceptual metaphors which contains RACISM IS A DISEASE and RACISM IS AN OPPONENT IN WAR Or RACISM IS AN OPPRESSOR (among others not mentioned in the present paper).

(82) Reconciliation starts here, among the people. This is where healing begins L01b

(83) The Truth and National Reconciliation Commission which will soon begin its work, is one important institution created by our democratic Constitution and Parliament in order to help us manage the more difficult aspects of healing the nation's wounds. nm95c

(84) The wounds of the period of repression and resistance are too deep to have been healed by the TRC alone, however well it has encouraged us along that path. nm98a

(85) It was also inevitable, given the nature of the divisions that do still run through our society, and the freshness of the wounds still to be healed that the judgements of such a body will jar with how some or others of us see matters. nm99a

(86) We reflect on the scars that all South Africans carry, marking the damage inflicted by a violent and inhuman system ${ }_{\mathrm{nm} 99 \mathrm{a}}$

(87) to heal the divisions of the past ${ }_{\mathrm{tm} 98 \mathrm{a}}$

(88) Because every time racial tensions in our rural areas become violent, it rips off the thin scab of reconciliation and reopens the wounds of the past ${ }_{\mathrm{L} 01 \mathrm{~b}}$ 
The negative experiences of racism under the apartheid system are conceptualised in (82) to (88) as physical injury. Although political and racist violence under apartheid rule led to many physical attacks, injuries and deaths, these are not referred to in the examples in (82) to (88). The expressions in these examples refer rather to the grief and psychological suffering caused by apartheid experiences. Psychological pain and injury is conceptualised as physical pain and injury, psychologically digesting an experience as the physical healing of wounds. The work of the TRC can be conceptualised within this metaphor as the cleaning of the wounds so that they can heal properly. Example (84) is linked to the metaphor RECONCILIATION IS THE DESTINATION OF A JOURNEY - the work of the TRC is thought of as a companion for a part of the journey who has "encouraged" the travellers to go on.

It is striking that more than half of the expressions stemming from the metaphor RECONCILIATION IS HEALING (6 out of the total 11 expressions in the corpus) were used by Mandela. This may be due to his personal experience of the grief and pain caused by racism and apartheid. Of the five politicians studied here, he is the one who directly experienced violence and humiliation at the hands of the enforcers of apartheid. Mandela's expression in (89) is related to the metaphor RECONCILIATION IS HEALING.

(89) In as much as reconciliation touches on every aspect of our lives, it is our nation's lifeline $_{\mathrm{nm} 99 \mathrm{a}}$

It emphasises the life-saving aspect of reconciliation - without reconciliation the South African nation would drown. It is related to RECONCILIATION IS HEALING as this also implies that without the healing of wounds the South African nation would not survive. Furthermore, it is linked to A NATION IS A PERSON and conceptualises past experiences of apartheid as water, therefore it is linked to RACISM IS A FORCE IN WATER.

\subsection{Conceptualisations of the ANC}

\subsubsection{Conceptualisations by the opposition}

The governing party is usually the object of much criticism, especially by the opposition. The sources used by the opposition to conceptualise the ANC carry mainly negative associations. The terms in which the internal organisation of the ANC is conceptualised by the opposition are illustrated in (90) and (91). 
(90) the ANC, where the leaders are ruling with an iron fist $\mathrm{K}_{\mathrm{N}} \mathrm{a}$

(91) I urge [the members of the ANC] to insist that their party should relinquish the most undemocratic clause in our new Constitution - the clause which makes them the captives of their partybosses. K97a

These metaphorical expressions lead to the underlying conceptual metaphor of THE ANC AS A DICTATORIAL ORGANISATION whose subjects cannot escape. This is however only apparent in one speech by De Klerk. Leon builds on the metaphor of A PARTY IS AN ENTITY, as in (92).

(92) the blurring of party and state created by the ANC's cadre deployment strategy and principle of "centralism" [...] It is part of a trend in South African politics that has spread like a cancer or virus. L01c

In this metaphorical expression the entities of party and state are no longer separated by clear boundaries - the borders have begun to disintegrate, to "blur". But two entities whose borders have ceased to exist are no longer two separate entities. This leads to the conceptualisation of South Africa being close to a one-party state. Moreover, the ANC is conceptualised as A MILITARY ORGANISATION (the ANC's cadre deployment strategy) which entails that it is organised by commands from an elite rather than by democratic voting. These conceptualisations seem to build on the experience of the years during which the ANC was an underground organisation and Umkhonto we Sizwe (MK, "Spear of the Nation") was still active. Since the view of the ANC as a military, communist and terrorist organisation was wide-spread in the apartheid years, this is a metaphor which will be easily followed by those parts of the electorate who have active memories of that time, thereby preventing different perspectives.

A conceptualisation of the ANC which is linked to the notion that the ANC wants to establish a one-party state is something like THE ANC IS A RAVENOUS BEAST, as in (93). It is a beast that follows its instinct (urge). It takes up other entities within itself (swallow) which then cease to exist as distinct entities; those it cannot eat it will at least destroy. ${ }^{3}$

(93) the ANC's urge to destroy that part of the opposition it cannot swallow K97a 
The conceptual metaphor underlying the expression in (94) by Leon is A POLITICAL PARTY IS A PERSON and more specifically THE ANC IS A (PLAYGROUND) BULLY.

(94) Or is this the new posturing of the playground bully who tries to protect his turf through insult and threat, using strong-arm intimidation [speaking of the $\mathrm{ANC}]_{\text {L01a }}$

This throws a different light on politics as a whole. Political parties are children who have quarrels on a playground. Seen from an adult's point of view these quarrels do not have anything to do with the "real world" and are relatively unimportant compared to other events in their world. The ANC is a child that is particularly strong, but has not yet learned to cope with this properly. It has not yet understood that physical intimidation (strong-arm intimidation) is not the only possible way of enforcing its will and moreover that talk and compromise are more highly valued as a means of interaction with others. This implies that the ANC has yet to be taught to behave according to the norms, possibly even by the other party-children. A superiority over the ANC is hereby claimed for the opposition by Leon (cf. Rohrer 1995: 120).

This conceptual metaphor also has its experiential background in the past connections of the ANC with the armed liberation struggle. However, this is the only instance of an expression hinting at this underlying metaphor in the corpus and might therefore as a structure of thought be limited to the DA or to Leon. But it may have been effective with those in the electorate whose main experience with the ANC was in connection with the armed liberation struggle.

Conceptualisations of the ANC by the opposition are still influenced to a large extent by the ANC's past. The ANC is still thought of in terms which highlight the militant and violent aspects of its past actions. The question of whether this conceptualisation of the ANC is limited to members of other parties, or whether ANC members also conceptualise the ANC in the same or similar terms could not be answered on the basis of the material in the present corpus. For this purpose, some expressions from an additional speech are analysed below.

\subsubsection{Conceptualisations by Mbeki}

The additional speech is one by Mbeki as the president of the ANC on the ANC's $88^{\text {th }}$ anniversary (Mbeki 2000a). The material from this speech has not been used in the analyses 
above; it is analysed here only with regard to conceptualisations of the ANC in order to get an initial impression of possible conceptualisations of the ANC by ANC members themselves. Mbeki uses the expressions in (95) to (97) in connection with the ANC.

(95) we must implement a vigorous cadre development programme to ensure that we have the necessary number of properly prepared cadres to ensure that the ANC remains the agent of revolutionary change it has always been

(96) we salute all members of the ANC, our Alliance, the rest of the democratic movement as well as the millions of our people for helping us to achieve this historic victory

(97) Apart from weeding out the corrupt elements from our ranks, to meet this strategic task $[\ldots]$

These expressions also lead to the assumption of a conceptual metaphor THE ANC IS A MILITARY ORGANISATION. But there is also evidence of different conceptualisations, as illustrated by the example in (98).

(98) the strengthening of our movement, the ANC, so that it is able to play its proper role as one of the architects of the African Century

Here the ANC is conceptualised as a constructive rather than a destructive force - as an architect it plans the future of the African continent. However, this is the only example supporting this conceptual metaphor.

Much of Mbeki's conceptualisations regarding issues of South African politics seem to be based on the notion of war. The metaphor THE ANC IS A MILITARY ORGANISATION could also be based on the metaphor POLITICS IS WAR, expressions of which occur frequently. However, taking into consideration the ANC's past, this appears to be the stronger influence. But to arrive at a definite conclusion, conceptualisations of other parties have to be considered, for which the present corpus does not provide sufficient material. 


\section{Conclusion}

This paper offers an initial analysis of the conceptual metaphors underlying contemporary South African political thought. Metaphors in South African political speeches form a complex systematic and coherent network structuring thought across party-political boundaries. The different mappings are interlocked - one target or one source domain can provide an anchor-point for multiple mappings which are thereby related to each other. Especially the metaphors used to conceptualise reconciliation are to a large extent linked closely to conceptualisations of racism. The links can often be recognised to work along logical inference patterns, such as in the case of RACISM IS A DISEASE and RECONCILIATION IS HEALING.

The majority of metaphors investigated here are shared by the five South African politicians, although they differ in the details. All view racism as something negative which needs to be resolved and reconciliation as something worth maintaining or striving for. Mbeki's conceptualisations very often draw on the source of war, whereas Leon and Van Schalkwyk prefer to use less openly violent metaphors. Some metaphors were used predominantly by one politician, which supports the hypothesis that conceptual metaphors are formed on the basis of an individual set of experiences.

Very few metaphorical expressions were found in the present corpus which could have their origin in traditional African culture rather than Western culture, or which have been transferred from African languages to English. There are a number of possible reasons for this, leading to a number of possible theses. It could mean that the language spoken at a given moment influences the selection of metaphorical concepts available, and that therefore the metaphorical concepts were very much alike across politicians, the language of all speeches being English. This possibility could be further investigated by making use of the Afrikaans parts of some speeches in the corpus. A second possible reason for the Western orientation of the metaphors analysed here is that Western culture and thought have had a devastating influence on African conceptual metaphors, at least in the field of politics. It could also simply be that Mandela and Mbeki, as representatives of African cultures in this study, have acquired Western structures of thought. This is especially possible in Mbeki's case, as he has had extensive contact with Western culture. 
Further research comparing the results of the present study to the concepts underlying European or North American political thought may be interesting. In the case of the metaphor underlying the efforts to unite the differing South African ethnic communities, it may be interesting to compare them to conceptual metaphors underlying political speech, thought and action of the German reunification. The speeches of the present corpus also provide material for a closer analysis of the development of conceptual metaphors within one speech or in connection with one issue. More research can also be done with respect to the question of whether metaphors give expression to "common sense", or whether they create the impression of "common sense", or perhaps both, to varying extents.

The questions raised and the theses proposed by this paper draw attention to the fact that much research still needs to be done in the field of metaphor. Such research is only justified if metaphor can hold its claim to be the principle structuring device of human thought.

\section{Notes}

1. Quote from the Sufi poet Ka'afir, cited as epigraph in Breytenbach 1986.

2. It seems more suitable to quote from the New Oxford Dictionary than to refer to academic definitions of and discussions on the term "war", since we are here concerned with the everyday use and understanding of the term.

3. If political parties (in South Africa) are conceptualised as persons, an interpretation in which the ANC is breaking the "taboo against cannibalism" (Rohrer 1995: 119) is possible.

\section{References: Speeches}

De Klerk, Frederick W. (South African Government Online)

Launch of the National Human Rights Trust, 20/03/1996 (K96c)

Inauguration of the Human Rights Commission, 21/03/1996 (K96d)

To Withdraw from GNU, 09/05/1996 (K96e)

Presidential Debate, 11/02/1997 (K97a)

Last Speech to Parliament, 09/09/1997 (K97b)

Leon, Tony.

Seeking an Antidote to Racism, 29/11/2000 (L00)

DA. <http://www.da.org.za/DA/Site/Eng/Speeches/speech.asp?ID=119> 
A Call for Tolerance, 25/03/2001 (L01a)

DA. <http://www.da.org.za/DA/Site/Eng/Speeches/speech.asp?ID=77>

A Call for Reconciliation, 14/04/2001 (L01b)

DA. <http://www.da.org.za/DA/Site/Eng/Speeches/speech.asp?ID=79>

In Defence of Freedom Gained, 27/04/2001 (L01c)

DA. <http://www.da.org.za/DA/Site/Eng/Speeches/speech.asp?ID=24>

Where in the world is South Africa? 05/09/2001 (L01h)

DA. <http:// www.da.org.za/DA/Site/Eng/Speeches/speech.asp?ID=201>

World conference against racism: double standards in Durban? 23/08/2001 (L01k)

DA. <http:// www.da.org.za/DA/Site/Eng/Speeches/speech.asp?ID=??>

Mandela, Nelson R.

Inauguration Address, 10/05/1994 (nm94) (South African Government Online)

Message on National Reconciliation Day, 16/12/1995 (nm95c)

ANC. <http://www.anc.org.za/ancdocs/history/mandela/1995/pr951216.html>

NP's Withdrawal from the GNU, 09/05/1996 (nm96b) (South African Government Online.)

Statement on Receiving the TRC Report, 29/10/1998 (nm98a)

Unwembi. <http://www.polity.org.za/govdocs/speeches/ 1998/sp1029.html>

Opening Address in the Special Debate on the Report of the TRC, 25/02/1999 (nm99a)

Unwembi. <http://www.polity.org.za/govdocs/speeches/1999/sp0225.html>

Mbeki, Thabo M.

Launch of the South African Human Rights Commission, 21/03/1996 (tm96)

ANC. <http://www.anc.org.za/ancdocs/history/mbeki/1996/sp960321.html

Opening of the Debate on Reconciliation and Nation Building, 29/05/1998 (tm98a)

ANC. <http://www.anc.org.za/ancdocs/history/mbeki/1998/sp980529.html>

Opening Session of the National Conference on Racism, 30/08/2000 (tm00b)

ANC. <http://www.anc.org.za/ancdocs/history/mbeki/2000/tm0830.html>

Opening of the NGO Forum of the World Conference Against Racism, 28/08/2001

(tm01b) ANC. <http://www.anc.org.za/ancdocs/history/mbeki/2001/tm0828.html>

Opening of the World Conference Against Racism, 31/08/2001 (tm01c)

ANC. <http://www.anc.org.za/ancdocs/history/mbeki/2001/tm0831.html>

ANC $88^{\text {th }}$ Anniversary Statement. 08/01/2000.

(South African Government Online) 
Van Schalkwyk, Marthinus.

Heritage is as much about the Future as it is about the Past, 24/09/2000 (S00a)

DA. <http:// www.da.org.za/DA/Site/Eng/Speeches/speech.asp?ID=172>

Debate on Racism, 28/09/2000 (S00b)

DA. <http://www.da.org.za/DA/ Site/ Eng/ Speeches/speech.asp?ID=168>

Unveiling of a Plaque for Gandhi, 30/01/2001 (S01a)

DA. Spaull, Robert H. <spaull@ natweb.co.za> "Reconciliation Speeches". 08.10.2001.

Personal e-mail. (08.10.2001)

Wreath at the Cradock Four Cenotaph, 05/02/2001 (S01b)

DA. Spaull, Robert H. <spaull@ natweb.co.za> "Reconciliation Speeches". 08.10.2001.

Personal e-mail. (08.10.2001)

Commitment to Non-Racialism and Reconciliation, 07/02/2001 (S01c)

DA. Spaull, Robert H. <spaull@ natweb.co.za> "Reconciliation Speeches". 08.10.2001.

Personal e-mail. (08.10.2001)

The Debate on White Guilt, 06/03/2001 (S01f)

DA. <http://www.da.org.za/DA/Site/Eng/Speeches/speech.asp?ID=139>

Task of Reconciliation, 14/03/2001 (S01g)

DA. <http:// www.da.org.za/DA/Site/Eng/Speeches/speech.asp?ID=??>

Political Identity and Reconciliation, 29/03/2001 (S01h)

DA. Spaull, Robert H. <spaull@ natweb.co.za> "Reconciliation Speeches". 08.10.2001.

Personal e-mail. (08.10.2001)

\section{References}

African National Congress. 2008. <http://www.anc.org.za/index.html> Maintained by Unwembi Communications. Accessed on 1 March 2008.

Breytenbach, B. 1986. End Papers. London: Faber and Faber.

Elman, J.L, E.A. Bades, M.H. Johnson, A. Karmiloff-Smith, D. Parisi and K. Plunkett. 2001. Rethinking innateness: A connectionist perspective on development. Cambridge: MIT Press.

Fauconnier, G. 1994. Mental spaces: Aspects of meaning construction in natural language. $2^{\text {nd }}$ ed. Cambridge: Cambridge University Press.

Fauconnier, G. 1997. Mappings in thought and language. Cambridge: Cambridge University Press. 
Fauconnier, G. and M. Turner. 2002. The way we think: Conceptual blending and the mind's hidden complexities. New York: Basic Books.

Gibbs, R. W. Jr. 1994. The poetics of mind. Figurative thought, language and understanding. Cambridge: Cambridge University Press.

Grady, J., T. Oakley and S. Coulson. 1999. Blending and metaphor. In R. W. Gibbs and G. J. Steen (eds). Metaphor in cognitive linguistics. Amsterdam: Benjamins. pp. 101-124.

Halisi, C.R.D. 1999. Black political thought in the making of South African democracy. Bloomington: Indiana University Press.

Lakoff, G. and M. Johnson. 1980. Metaphors we live by. Chicago: University of Chicago Press.

Lakoff, G. 1982. Metaphor and communication. Trier: Linguistic Agency University of Trier. Series A. Paper No. 97.

Lakoff, G. 1989. The invariance hypothesis: Do metaphors preserve cognitive topology? Duisburg: Linguistic Agency University of Duisburg. Series A. Paper No. 266.

Lakoff, G. 1992. Metaphor and war: The metaphor system used to justify the war in the Gulf. In M. Pütz (ed). Thirty years of linguistic evolution. Amsterdam and Philadelphia: John Benjamins. pp. 463-481.

Lakoff, G. 1993. The contemporary theory of metaphor. In A. Ortony (ed). pp. 202-252.

Lakoff, G. 1996. Moral politics. What conservatives know that liberals don't. Chicago and London: The University of Chicago Press.

Ortony, A. (ed). 1993. Metaphor and thought. $2^{\text {nd }}$ edition. Cambridge: Cambridge University Press.

Rohrer, T. 1995. The metaphorical logic of (political) rape: The New Wor(1)d Order. Metaphor and Symbolic Activity 10(2): 115-137.

Rumelhart, D. E. 1993. Some problems with the notion of literal meanings. In A. Ortony (ed). pp. 71-82.

South African Government Online. 2008. <http://www.gov.za/index.html> by Government Communications (GCIS). Accessed on 1 March 2008.

The New Oxford Dictionary of English on CD-Rom. 2000. Oxford: Oxford University Press.

Unwembi Communications (www.unwembi.co.za). 2007. Unwembi's Resource of South African Government Information. <http://www.polity.org.za> Accessed on 1 March 2008. 